\title{
Research on the Application of Modern Apprenticeship System in Mechanical and Electrical Integration Technology in Higher Vocational Colleges
}

\begin{abstract}
Yin $\mathrm{Li}^{1}$
'Jiangxi Vocational Technical College Of Industry \& Trade, Jiangxi, Nanchang, 330038

739960103@qq.com

ABSTRACT

The application of modern apprenticeship in higher vocational colleges can not only enable students to obtain internship positions in enterprises, but also enrich their own practical experience and practical operation process. Therefore, in higher vocational colleges, proper reform and development of talent training models should be carried out, schoolenterprise cooperation should be implemented, professional assessment models should be changed, the creation of teacher teams should be improved, the role of modern apprenticeship should be brought into play, and the integration of mechatronics Technical students can strengthen their own practical and operational capabilities, thereby improving their own comprehensive level, enhancing their competitiveness, and promoting the professional progress of the school.
\end{abstract}

Keywords : mechatronics, modern apprenticeship, practice

\section{现代学徒制在高职机电一体化技术专业中的应用探究}

\section{李殷 ${ }^{1}$}

\author{
${ }^{1}$ 江西工业贸易职业技术学院 江西 南昌 330038 \\ 739960103@qq.com
}

\section{摘要:}

将现代学徒制应用在高职院校中, 不仅可以使学生获得企业的实习岗位, 还可以丰富自身的实践经验和实践操 作过程。所以，在高职院校中应该对人才的培养模式进行适当的改革发展，实行校企合作，改变专业考核模式， 完善师资队团队的创建工作, 发挥出现代学徒制的作用, 让机电一体化技术专业的学生可以强化自身的实践操 作能力，从而提高自身的综合水平，增强竞争力，推动学校专业进步。

关键词:机电一体化; 现代学徒制; 实践

\section{1.现代学徒制概述}

高职院校主要采用学徒制作为技术人才的培养 模式, 这是一种借鉴国外的、先进的、创新的教学培 养方式。学徒制是否与我国高职机电一体化技术专业 相互适应, 也是一个需要深度探索的问题。只是我们 使用的教学模式并不能直接照搬国外, 而是要根据我 国的实际状况对教学模式进行创新, 使其为我所用。

西方国家是最早使用现代学徒制作为人才培养 模式的, 最近几年才真正的应用于我国的高等院校。 理论教学和实践教学相互结合是现代学徒制的特点, 这种教学模式被企业和学校共同推进。应用这样的教
学模式, 对学生综合素质的提高发挥着重要的作用, 还能让学生学以致用。实际操作就是指学生在企业进 行实践, 在专业人士或者是工作人员的指导下, 依靠 自己动手操作来掌握相关的操作技能, 把课本理论知 识转化为自己的技能, 提高自己的实践操作能力。另 外, 这段学徒经验也可以作为社会工作经验, 有助于 更好的就业。这几年来, 我国在个别的省市应用现代 学徒制, 挑选出几个试点对这种教学模式进行试验, 希望这种教学模式与我国的人才培养目标相互适应, 适合我国高职院校，为社会发展提供更多的技术人才。 而对于机电一体化技术专业来说, 理论与实际的相互 结合也显得尤为重要。 


\section{2.学徒制对于机电一体化专业的重要性}

\section{1 使学生在实践中理解理论知识}

高职院校是一个培养技术型人才的场所, 不仅要 提高学生的专业素养, 还要提高学生的实践能力。但 现阶段大部分高职院校的技术型特征正在逐渐消失, 它们更注重提高学生学习理论知识的能力, 不再注重 提高学生的实践能力。现阶段大学生的课程是以理论 知识为主, 考试内容也以理论知识为主, 这导致学生 越不越不注重提高自己的实践能力, 这些现象并不利 于高职院校的发展。高职院校是一个培养技术型人才 的场所, 相较于普通院校来说, 高职院校的优势就是 可以更好地培育学生的实践能力, 使学生在毕业后可 以快速的适应工作岗位, 但如果学生的实践能力不足, 学生将不会有一个良好的就业前景。步入 21 世纪以 后, 随着新课程的不断改革, 高职院校不仅要提高学 生的专业素养，还要提高学生的实践能力。

机电一体化技术专业主要是以实践为主要任务, 机电一体化技术专业的学生若知识了解理论知识而 实践能力差是无法在本专业工作岗位上任职的。机电 一体化技术专业的学生可以在机械设备的维修, 调试 等岗位上工作, 是技术应用型的人才。因此, 需要有 效的运用现代学徒制, 为学生提供更多的实践机会, 把理论知识和实践相结合, 使实践技术熟练于心。特 别是专业化的技术都会操作才可以顺利的进入实习 岗位, 找到满意的工作

\section{2 将实践任务放入教师，实现教学和实践一 体化发展}

机电一体化技术专业是工科学科的一类, 工科学 科体现出最大的特点是具有较强的实践性。因此, 对 于机电一体化技术专业的学生来说, 通过参与实践活 动的方式来锻炼自身实践能力使非常有必要的。对于 高职院校中机电一体化技术专业的学生来讲, 一定要 掌握操作技能, 只有掌握操作技能, 才可以在市场上 体现出更强的竞争优势。然而, 学徒制的应用给高职 院校的学生带来了参加实践的机会, 学生可以在企业 或工厂内进行实践, 并且在过程中积攒有价值的实践 经验。学生在参与实践的过程中, 同时也是在实际践 行自己在专业课程中学习到的理论知识, 有助于更好 地理解并掌握理论知识, 也能够学到一定的基本操作 技能, 在学习过程中是非常有意义的一环。相较于传 统的人才培养模式, 现代学徒制在培养高职院校学生 方面更加具有优势, 同时也更有利于工科专业学生进 行专业课程的学习。不过, 学生在企业或工厂中参与 的实践活动, 并不能替代学校模拟实践的重要作用, 学校开展的模拟实践活动对学生来讲是非常有价值 的, 也是不可替代的。

\section{3 学徒制提升学生的适应性}

当今很多应届生在工作中会遇到实践经验不足 的情况, 虽然掌握了必要的理论知识, 但在工作实际 应用中感到难以胜任。有很大原因归结于高校的教学 模式: 目前很多院校采用的教学模式仍是传统性的, 课上以教师为主导, 学生被动接受知识, 师生之间互 动性差, 为学生安排的实践机会也不多, 在这样的教 学模式中学生无法真正实践。另外, 一些学生理所当 然的认为届时工作会安排培训, 到时在积累实践经验。 这种想法是片面的、狭险的。一些具有前瞻性的学生 在大学中就积累了工作经验, 在择业时就已领先。尤 其是在招聘机电一体化专业等工科专业毕业生时, 此 类学生会更受青睐。所以, 学徒制就很好得缓解了以 上问题。学徒制为学生创造实践机会, 让学生真正了 解企业的用人需求。如此, 学生就会意识到自己与其 差距, 提前做好心理和行动准备, 并用心把握实践机 会, 不断积累实践经验, 在以后真正就业时也不会感 到难以胜任了。

\section{3. 高职机电一体化技术专业现代学徒制实践 探索研究}

\section{1 学徒制下培养学生的专业实践能力}

学徒制, 顾名思义, 由师傅带徒弟进行技术学习 的制度。而现代学徒制是学校和企业深度合作，校内 理论教师和校外技术师傅联合传授, 对学生以技能培 养为主的现代人才培养模式。现代学徒制和普通的大 专班的人才培养目标和培养模式不同, 现代学徒制注 重理论结合实践, 强调技能的传承。现代学徒制由学 校和企业合作培养现代化专业人才，校企制定全面、 规范的企业课程标准以及完善的考核评价体系, 由此 可见, 现代学徒制是校企深度合作的现实表现。对于 机电一体化技术专业而言, 学校主要将该工科专业的 教育划分为三大阶段: (1)第一阶段, 机电一体化技术 专业学生在该阶段主要学习专业理论知识, 充分学习 本专业的知识内容, 构建较为完善的专业知识体系, 在坚实的专业知识基础上, 学校为学生设置短期的基 础技能培训, 在该期间, 学校将邀请校外的机电一体 化技术专家为学生开展教学活动, 让学生初步了解机 电一体化技术的就业现状、就业需要和相关企业的环 境。(2)在第二个阶段, 学生的理论知识学习比重逐渐 下降, 专业技能实践学习的比重逐渐上升, 学校安排 长期的专业技能实践培训, 在此期间, 学生需要熟练 掌握专业技能和工作岗位要求。(3)第三个阶段为实习 阶段, 经过大量的理论学习和专业技能培训, 学生正 式进入实践阶段, 学校为学生联系企业或者工厂, 学 生直接以学徒身份进入企业或工厂的相关岗位, 当然, 实习阶段的培养方式要尊重学生意愿。在第三阶段, 学生在企业或工厂中会有指导自己工作的师傅, 带领 学生快速熟悉工作内容, 让学生传承工作技能、锻炼 坚强意志、培养实践能力。 
经过上述的三个现代学徒制培养阶段, 机电一体 化技术专业的学生将在完善的专业理论知识体系中 逐步锻炼、提升自己的专业基础能力和专项能力以及 综合能力。学生可以在企业或工厂中学习师傅的工作 方式和工作技能, 在观察的基础上自己动手操作, 真 切认识和体会自己的专业能力。

\section{2 学校企业深度合作，共同培养专业人才}

现代学徒制的人才培养模式离不开企业的支持 与配合, 学校需要和企业合作, 企业为学生提供良好 的实践场所和充分的实习条件。然而, 学校和企业如 果不深度合作, 只是简单的进行单次合作, 等下一批 学生即将需要实习场所时, 学校再为学生重新联系可 供实习的企业, 这必将带来大量的损耗, 同时也为学 生的实习带来不稳定因素。因此, 学校要与企业达成 共识, 共同培养机电一体化专业人才, 学校与企业相 互信任, 通过努力, 实现长期且稳定的深度合作。在 长期的深度合作中, 企业会更加熟悉学校的专业内部 情况和学校学生的知识水平与实际能力, 企业将安排 更加合适的技术工作人员为学生的“师傅”, 师傅采用 针对性方式带领学生进行实习实践活动。

学校与企业合作的根本目的是丰富学生的实习 工作经验和提升学生的实践能力, 学校和企业深度合 作, 按照共同的培养目标和方向对学生进行针对性的 培养。学校重点帮助学生构建完善的专业知识理论体 系和锻炼学生的专业基本能力, 企业则负责培养学生 的专业工作技能以及职业综合能力。对于学校而言, 校企合作大大提高了学生的专业能力, 有利于提高学 校专业教学的质量和毕业生就业率; 对于企业而言, 校企合作有利于企业提前熟悉学校专业的学生, 由于 学生在企业实习过较长时期, 熟悉企业的工作流程, 引入学校毕业的专业人才, 有利于企业节省培训的时 间和经费，可快速吸纳为上岗的工作人员。

\section{3 校企共同协定考核模式}

近年来, 大部分高职院校采用笔试的方式对机电 一体化技术专业学生进行考核, 而机电一体化技术专 业的培养核心在于要求学生理论知识与实践结合, 实 践能力尤为重要, 单一的笔试考核方式无法全面的考 查机电一体化技术专业学生的专业综合能力。因此, 将实践能力的考核内容纳入传统机电一体化技术考 核体系中是十分必要的。当然, 对于学生的实践能力 考核, 学校要与企业达成合作, 有企业负责学生的专 业实践技能水平的考核方式和考核内容。企业可以将 以下方面对学生实践能力进行综合评价: (1)学生的实 习出勤情况 (2)工作操作熟练程度 (3)操作的正确率 (4) 实习的学习认真程度(5)与“师傅”的学习态度等, 将几 个方面进行科学比例的加权方式算入学生的总分。由 此可让学生在企业实习阶段更加努力刻苦的学习专 业技能, 更加重视实习阶段的学习。

\section{4 加强师资队伍建设}

目前, 现代学徒制的教学模式需要大量的专业教 师, 学校对教师的要求会有所提高。学校在培养机电 一体化技术专业学生的专业基础技能时, 需要具有丰 富实践经验的教师带领学生学习, 对学生进行专业的、 针对性的技能培训。学校可以与企业合作, 引入企业 的专业技术人才, 由其兼职学校教师, 前往高校为学 生进行专门培训。当然, 在合作企业引入的专家教师 熟悉企业的内部实习流程, 有利于提前为学生步入企 业实习打好基础。所以，建议高校组建校内教师和校 外技术专家共同组合的机电一体化技术专业师资队 伍。

\section{4. 结论:}

在现代学徒制下, 学校要积极寻求与企业的深入 合作，为学生提供充足的实践机会以提升专业技术实 践能力。机电一体化技术专业学生应重视锻炼专业技 能和培养实践能力, 珍惜学校和企业提供的实习机会, 利用良好的实习场所和实习条件, 努力学习企业工作 岗位的相关需求和工作流程, 熟练掌握专业操作。学 校与企业深度合作，共同探索针对性的专业人才培养 模式, 构建完善的学生专业综合能力考核评价体系, 合作组建专业的师资队伍, 充分发挥学徒制的制度优 势, 促进机电一体化技术专业学生锻炼专业操作能力, 提升专业实践能力, 增强竞争力, 学校和企业在学徒 制下也能实现共赢。

\section{REFERENCES}

[1] $\mathrm{Xu}$ Yueqing. Exploration and practice of the innovation of the five-year higher vocational talent training model. A case of Wuxi Mechatronics and other vocational technical schools [J]. Going Abroad and Employment: Employment Education, 2011(20): 51-52.

[2] Wang Deshan, Shao Jianping, Xu Huiyin, Li Jie, research and practice on the construction of a higher vocational "school-enterprise integration, integration of engineering and learning" talent training model[J]. Vocational Technology, 2012(8): 35-36.

[3] Liu Qiaozhi and Xu Li. Research and Practice of Higher Vocational Talents Training Model Based on Modern Apprenticeship One Taking Food Nutrition and Testing as an Example []. Agricultural Products Processing (Part 2), 2015, 0(4): 81-84.

[4] Han Yuhui and Zhang Qingling. Exploration and practice of "dual tutor" team construction in higher vocational education based on modern apprenticeship []: China Vocational and Technical Education, 2018, 0(34): 88-90. Cited: 21 
[5] Wang Jiming, Wang Yanni, Li Chuanwei. Research on the "4 Fusion" talent training model based on modern apprenticeship []. Journal of Jincheng Vocational and Technical College, 2015, 8(4): 2023

[6] Hu Yan, Duan Xiaole. Comparative study on the role of industry associations in the development mechanism of modern apprenticeship curriculum system at home and abroad []. Journal of Taiyuan Urban Vocational College, 2016, 0(2): 7-8.

[7] Yao Xiaoqiang, Fan Tonghua and Guan Lin Dong. Research on the "Three-in-One" Talent Cultivation Model of the Five-Year Higher Vocational Die Design and Manufacturing Specialty []. Contemporary Vocational Education, 2016, 0(8): 80-83.

[8] Kang Xiaomeng and Shen Fazhi. Thoughts and Strategies for Practicing Modern Apprenticeship in Petrochemical Specialty in Higher Vocational Education--Taking Yangzhou Vocational College of Industry as an Example [J].Journal of Jilin Institute of Chemical Technology, 2016,33(10):51-54 .

[9] Practical research on the talent training model of six integration of engineering and learning under the vision of Hui modern apprenticeship--Taking Wuxi Mechatronics Higher Vocational and Technical School as an example []. Vocational Education Newsletter, 2014, 0(32): 9-11.

[10] Ye Ke, Lu Jingbing, Zhu Gang, Wang Fang. Innovative practice model to promote modern apprenticeship-Taking Beijing Agricultural Vocational College Automobile Inspection and Maintenance Technology as an example [] Journal of Beijing Agricultural Vocational College, 2016, 30(6): $67-72$.

[11] Wei $\mathrm{Na}, \mathrm{Hu}$ Xiaoli. Based on the analysis of higher vocational talent training mode under the modern apprenticeship system. A case study of electromechanical integration specialty [].Human Resource Development 2016,0(22):189-189.

[12] Zhang Qingling. Research and Practice of Enterprise Curriculum Construction under the Background of Modern Apprenticeship-Taking the Urban Rail Transit Specialty "Urban Rail Vehicle Experiment and Driving" course of Changchun Vocational and Technical College as an example [J].Journal of Nanning Vocational and Technical College, 2017, 22 (1):35-38.

[13] Zhu Rensheng The innovation of the talent training model of "Six integration of engineering and learning" in Jiangsu five-year higher vocational electromechanical and physical technology [J]. Education and Vocation, 2017, 0(7): 103-107.

[14] Song Qunling, Teng Yu, Li Yingjuan, Zhang Wenli, Cai Chuanxiong. Discussion on the "Order Apprenticeship" talent training model for metallurgical technology majors in higher vocational education[]. China's off-campus education: late, 2017,0(4):154-155.

[15] Zhang Guiyuan. Research on the establishment of curriculum standards for modern apprenticeship enterprises_- Taking the course of "urban rail transit control position practice" as an example [J]. University: Teaching and Education, 2020(11): 45-47. 